Ann. Parasitol. Hum. Comp., 1991, $66: \mathrm{n}^{\circ} 2,54-56$.

Mémoire.
Key-words: Hymenolepididae. Shrews. Diplomesodon. Middle Asia.

Mots-clés : Hymenolepididae. Musaraignes. Diplomesodon. Asie Centrale.

\title{
PSEUDHYMENOLEPIS TURKESTANICA SP. N. (CESTODA: HYMENOLEPIDIDAE), A NEW CESTODE FROM SHREWS
}

\author{
V. V. TKACH*, V. P. VELIKANOV**
}

SUMMARY

An illustrated description of the Pseudhymenolepis turkestanica sp. n., a new cestode from piebald shrew (Diplomesodon pulchellum) from Middle Asia is given. P. turkestanica differs from the most similar species $P$. papillosa Hunkeler, 1970 by the mea- sures of the scolex and rostellum, the number of rostellar hooks and the size of embryonic hooks. P. turkestanica is considered as a specific parasite of $\dot{D}$. pulchellum.

RÉsumé : Pseudhymenolepis turkestanica sp. n. (Cestoda, Hymenolepididae), un nouveau cestode de musaraigne.

L'article contient la description illustrée d'un nouveau cestode. Pseudhymenolepis turkestanica sp. n. chez les musaraignes Diplomesodon pulchellum d'Asie Centrale. P. turkestanica diffère de l'espèce la plus proche, $P$. papillosa, par les dimensions du scolex et du rostre, par le nombre des crochets du rostre ainsi que par les dimensions des crochets de l'oncosphère. P. turkestanica est considéré comme un parasite spécifique de $D$. pulchellum.
Cestodes of the genus Pseudhymenolepis Joyeux and Baer, 1935 were unknown from the territory of the USSR until recently. In the course of investigation of shrews helminths in Middle Asia a new species of Pseudhymenolepis was recovered from piebald shrew (Diplomesodon pulchellum). Morphological structure of cestodes was studied on total preparations stained with lactocarmine or iron acetocarmine (Georgiev et al., 1986) and mounted permanently in Canada balsam. Some of the scolices wer embedded in the Berlese medium which facilitated a precise study of the hook shape and size.

Pseudhymenolepis turkestanica sp. n. (Fig. 1).

Host: Diplomesodon pulchellum Lichtenstein, 1823 (Insectivora: Soricidae).

Localization: intestine.

Localities: shores of lake Sarykhamysh (type territory), southern part of Central Karakum desert, Sundukli sands (all places in Turkmenia); desert south to lake Balkhash (in Kazakhstan).

Material: 19 specimens, 16 specimens of cestodes were recovered from 6 of 26 studied hosts in Turkmenia and

* Institute of Zoology of Ukr., Acad. Sci., Lenin st., 15, Kiev-30, 252601 USSR.

** Turkmenian antiplaque station, Ostrovsky st., 18, Ashkhabad, 744020 USSR

Accepté le : 6 juin 1991.
3 specimens from 1 of 5 hosts in Kazakhstan. Holotype: preparation no. 288, Diplomesodon pulchellum, Sarykhamysh, 4.05.80; paratypes on the same glass (type material is preserved in the helminths collection of Dept. of Parasitology, Ukr. Acad. Sci. Institute of zoology).

The species is named according to the region where it was found.

Description (measurements of holotype are given, data about other specimens are in brackets). All measurements in micrometres.

Small hymenolepidids. Strobila length is unmeasurable because the strobila falls into separate proglottids in host intestine. Only few of younger proglottids are usually connected with scolex. Scolex $75 \times 105(70-75 \times 80-105)$. The round suckers $37-40(35-44)$ in diameter. The rostellum is pear-shaped, $45 \times 35(31-38 \times 28-32)$, its anterior surface is flattened and posterior part is conical. Rostellar sac $72 \times 47(62-67 \times 38-45)$, its bottom extends below the suckers level. Rostellum bears a simple crown of 17 hooks. Hook length 18 (18-20). Handle thin, nearly straight, 9-10 (9-11) in length. Blade curved, 9 in length. Guard 6 in length, with somewhat thickened lower edge.

Neck 63 (58-75) in width, not distinctly demarcated from scolex. Proglottids are not numerous. Excretory ducts are very thin.

Hermaphroditic proglottics measurements $32 \times 14$ (31-38 $\times 12-17)$. Three round testes are arranged in a 

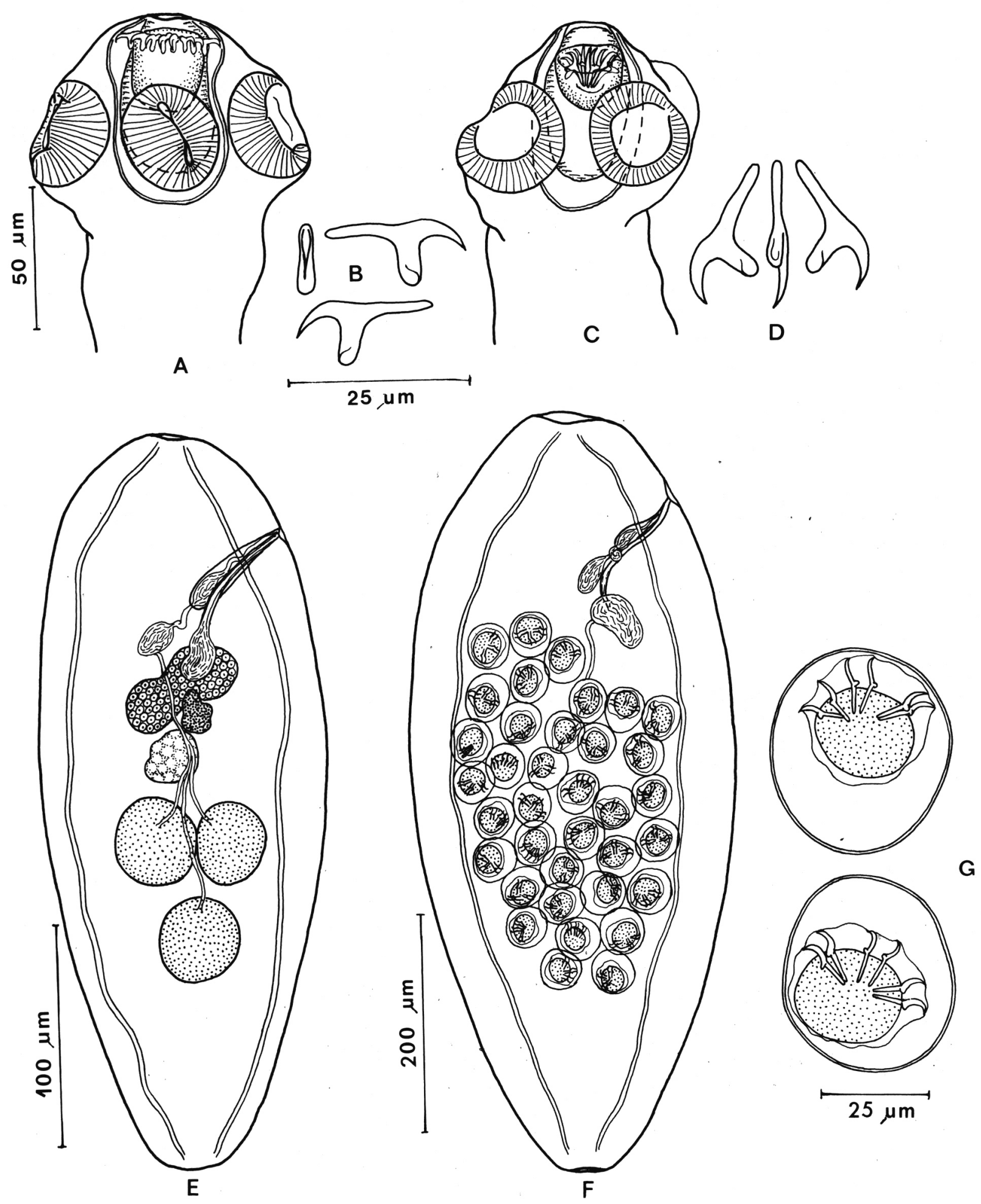

FIG. 1. - Pseudhymenolepis turkestanica sp. n. from Diplomesodon pulchellum.

A, C: scolices; B, D: rostellar hooks; E: mature proglottid; F: gravid proglottid; G: eggs (A, B, E, F: holotype; C, D: material from Kazakhstan). 
triangle, their diameter 38-43 (41-50). Cirrus sac $60 \times 13$ $(62-70 \times 14-17)$. Cirrus sac crosses the poral excretory ducts and opens into the genital atrium located approximately at $1 / 6$ of the right edge of proglottid. Genital pores are one-sided. External seminal vesicle $23 \times 15$ $(24-30 \times 15-20)$, crossed the medial line of the proglottid. Internal seminal vesicle fills the proximal part of cirrus sac. Cirrhus thin, unspined. There were no proglottids with fully evaginated cirrus in the material.

Ovary is $60 \times 28(50-53 \times 30-32)$, bilobed. It situated in the upper part of the proglottid. Vitelline gland is under the ovary, $18 \times 15$ in size. Comparatively small seminal receptacle $25 \times 17(26-28 \times 18-22)$ in size. Vagina $68(50-55)$ in length, opens into the genital atrium ventral to male genital pore. Both the cirrus sac and the vagina are located dorsal to the longitudinal excretory ducts. Sac-like uterus is between the ovary and testes. Its development was not elucidated in detail because of somewhat insufficient material (not all the stages of uterus development are presented out collection).

Gravid proglottids measurements $69 \times 31$ (56-84 $\times$ 27-35). Each proglottid contains 30-40 eggs occupying space between excretory ducts. Eggs are round, 41-45 (38-43) in diameter. Medial and lateral embryonic hooks measurments are 15 and 16-17 respectively. Medial hooks are distinctly thinner than lateral ones.

In gravid proglottids of $P$. turkestanica as well as in the same ones of another species $P$. redonica (from the territory of Ukraine) we have not found egg capsules like those described by Joyeux and Baer (1936) and some other authors for Pseudhymenolepis. One the basis of this feature the subfamily Pseudhymenolepidinae was separated. We suppose that the well-developed embryophore of Pseudhymenolepis could be taken for the egg outer shell whereas the true egg outer shell could be taken for the egg capsule membrane. The fact that the egg measurements of $P$. redonica in our material are corresponding to the measurements of uterine egg capsules given by Joyeux and Baer (1936) is in favour of this assumption. Detail study of the fine structure of pregravid and gravid proglottids is necessary in order to solve this important question finally.

Differential diagnosis. There are 5 species of Pseudhymenolepis ( $P$. redonica Joyeux and Baer, 1935; $P$. eburnea Hunkeler, 1970; P. papillosa Hunkeler, 1970; P. solitaria (Meggit, 1927); P. graeca Vaucher, 1984) were known until now. They are very similar in morphology and development of the proglottids, but differ one from another primarily by the number and size of rostellar hooks. In this respect $P$. turkestanica is closely resembling to $P$. papillosa, described from Crocidura flavescens spurelli in Ivory Coast (Hunkeler, 1970). These two specimens ae distinctly distinguishable by the measures of scolex (147-160 in $P$. papillosa) and rostellum (43-47 $\times$ 47-54 in $P$. papillosa), the number of rostella hooks (19-22 in P. papillosa) and the size of lateral embryonic hooks (only 12 in P. papillosa).

Besides that, the areas of two species are extraordinarely distant one from another. Finally, $P$. turkestanica parasitizes the piebald shrew-the only living representative of the genus Diplomesodon-endemic for the Middle Asia. Presumably, $P$. turkestanica is a specific parasite of this host because it was not found in any other shrew species from the same region.

\section{REFERENCES}

Georgiev B., Biserkov V., Genov T. : In toto staining method for cestodes with iron acetocarmine. Helminthologia, 1986, 62, 235-240.

Hunkeler P. : Deux Pseudhymenolepis nouveaux (Cestoda, Hymenolepididae) chez les Musaraignes de Côte-d'Ivoire (Note préliminaire). Zool. Anz., 1970, 184, 125-129.

Joyeux C., Baer J. : Cestodes. In: Faune de France, Paris, 1936, $613 \mathrm{p}$. 